\section{Why are AIDS dissidents still making 15-year-old, long-refuted claims?}

Sir - The attempt by Stewart et al.

(Nature 407, 286; 2000) to minimize the significance of the recent Durban

Declaration (Nature 406, 15; 2000)

affirming that HIV is the cause of AIDS

raises several troubling issues.

Stewart et al. suggest the bulk of the declaration's 5,000 academic signatories may have inadequate credentials. Yet the signatories of the Stewart et al.

Correspondence, who make up most of the 'HIV-denialist' membership of President Mbeki's AIDS advisory panel, are mainly known for their disagreement on AIDS with just about everyone else in academic science, medicine and public health. In contrast, the signatories to the Durban Declaration include the vast majority of scientists worldwide who publish on all aspects of HIV and AIDS.

Second, Stewart et al. distort the declaration's statement that there is "no end in sight" to the epidemic by taking the phrase utterly out of context. Enormous progress has, of course, been made against AIDS, all of it stemming from the fundamental knowledge that AIDS is directly caused by HIV infection. This knowledge has enabled a long string of consistent and fruitful observations about the pathogenesis of HIV and brought about a powerful new family of pharmaceuticals that, however imperfect, have dramatically reversed the death rate from AIDS wherever they have been used.

There is "no end in sight" only where poverty, greed, politics or misguided information blocks access to these advances. Sadly, people in developing nations are paying the price with their lives, nowhere more so than in South Africa. Women are being deprived of safe, proven methods of blocking neonatal transmission, efforts to improve access to the new drugs are being undermined and years of prevention work are being confounded.

Third, Stewart et al. cite four papers from the early 1980s as a basis for objecting to the Durban Declaration. Whatever such papers say, they reflect only the knowledge available when they were written.

Subsequent data have greatly refined our understanding. Why do Stewart et al. ignore 15 years of scientific progress?

Fourth, Stewart et al.'s claim that AIDS did not spread initially in Africa is simply incorrect. While the spread of HIV-1 and AIDS to sub-Saharan Africa was a later phenomenon, AIDS appeared in significant numbers more or less concur- rently in several other African nations, Europe and North America in the early 1980s. Heterosexual transmission was evident almost from the beginning in Africa, as well as among transfusion recipients and haemophiliacs. Fear of an outbreak among Western heterosexuals was a valid concern. We were extremely fortunate in the United States to have a slow initial spread to heterosexuals, probably because the epidemic first broke out exponentially here among homosexual men, who do not routinely have sex with women. This observed pattern of HIV-1 spread is exactly what would be expected of a sexually transmitted disease with a first foothold in the gay male community. Today, heterosexual transmission is routine almost anywhere HIV-1 appears.

Although there may be some disparities in the ways AIDS affects people in developing nations compared with the West, there are no great mysteries. Higher rates of breast-feeding, for example, together with malnutrition and poor prenatal and delivery care, undoubtedly contribute to a higher rate of infant infection. The fact that many people in Africa have been unable to use prophylactic antivirals has also contributed enormously to the disparity in the rate of perinatal transmission compared with the West.

Finally, Stewart et al. argue that the HIV-denialists have had their views suppressed. On the contrary, scientists worldwide have shown excessive patience for the past 15 years. The accepted standard of science is to permit everyone to express their views, but also to hold people intellectually responsible for what they say. When a position is found faulty by the consensus of scientific opinion, principled dissenters go back to the lab and run new experiments in hopes of proving their point on a new day, rather than attacking the character of their critics and arguing their case to scientifically unqualified media and the lay public. The HIV-denialists are preaching to the very people at greatest risk now, the HIVpositive patient population itself.

Thousands of babies are born with HIV infection in South Africa alone, with little or no hope of a normal life. How high will the death toll have to be before the denialists see the error of their ways? Martin Delaney

Project Inform, 205 13th Street, Suite 2001, San Francisco, California 94103, USA Other signatories to this letter:

Linda Grinberg Foundation for AIDS and Immune Research, Los Angeles, California, USA

Mark Harrington Treatment Action Group, New York, USA

Lynn Morris National Institute of Virology, Johannesburg, South Africa Mark A. Wainberg McGill University AIDS Centre, Montreal, Canada John P. Moore Joan and Sanford I. Weill Medical College of Cornell University, Ithaca, New York, USA

\section{Mildest organochlorines still cause toxic pollution}

Sir-In his Correspondence about a recent book review, Ferdinand Engelbeen ${ }^{1}$ criticizes Joe Thornton ${ }^{2}$ for failing to distinguish between good and bad organochlorines, without proposing how one might do so at reasonable cost. One of the strengths of Thornton's book ${ }^{3}$ lies in its account of the exceptional difficulty of this process and the many ways we have failed to understand the implications of synthesizing chemicals that have no part in natural cycles.

Rather than undermining the case for restrictions based on chemical classes, Engelbeen's own example of PVC illustrates why it is so hard to regulate chemical compounds on an individual basis. Thornton argues that organochlorines, as a result of their fundamental chemistry, tend as a class to be greatly more persistent, more toxic and more bioaccumulative than their nonchlorinated relatives. Hence when degradation does occur it usually results in the production only of smaller organochlorines. Even organochlorines that are non-toxic or benign (such as PVC) are end-products of a sequence of reactions that at each stage result in the production of large quantities of toxic, persistent and uncharacterized chlorinated intermediates, by-products and wastes.

To make matters worse, even with the best available methods, organochlorines cannot be disposed of without the production of yet more toxins. PVC, via incineration, is probably ultimately the major environmental source of dioxins ${ }^{4}$. Nor is PVC always likely to be disposed of by the best methods. Significant quantities (even in the developed world) are disposed of in bonfires, building fires and rubbishtip fires, and these too are likely to be important sources of dioxins and other chlorinated toxins ${ }^{4}$.

Jonathan R. Latham

6 Canon Frome Court, Canon Frome,

Ledbury HR8 2TD, UK

1. Engelbeen, F. Nature 407, 445 (2000).

2. Collins, C. Nature 406, 17-18 (2000).

3. Thornton, J. Pandora's Poison: On Chlorine, Health and a New Environmental Strategy (MIT, Cambridge, MA, 2000). 4. Thomas, V. \& Spiro, C. Toxicology and Environmental Chemistry 50, 1-7 (1995).

\section{Ancestors knew how to harness horsepower ...}

Sir — Vaclav Smil's Millennium Essay "Horse power" (Nature 405, 125; 2000) came as a pleasant surprise to me, as I would not have imagined that the readers of Nature were interested in this topic. 
However, it is not true that "ancient throat-and-girth harnesses choked the animal". This mistake was first made in the 1920s by Richard Lefebvre des Noëttes. His theory that slavery stemmed from the inability of the ancients to use animal power efficiently was very popular in his day. It lingers on in popular literature, although it has long been disproved: as Jean Spruytte showed in the 1970s, there were several ways of harnessing horses in antiquity, none of them choking the animals, and there is no connection between animal harnessing and slavery. (See, for example, Spruytte's Early Harness Systems, J. A. Allen, London, 1982.) Lefebvre des Noëttes had two different harnessing techniques mixed together in his mind. So Smil is right that the horsecollar was an improvement, but only an improvement on a existing technique.

Second, as far as one can tell, ancient and medieval horses were very small, often barely the size of present-day ponies. There is no incontrovertible evidence of the breeding of "heavy war animals needed to carry armoured knights" that has so often been supposed. In medieval times, large horses were a rare luxury. We lack the data on horse size to know what happened before the eighteenth century, so we cannot know whether armoured knights did ride big horses.

My last point concerns ploughs. The replacement of wood by iron and steel obviously allowed many improvements in the general structure and design of ploughs. But the case of mould-boards is special. The idea that "iron mould-boards only crossed from China to Europe in the seventeenth century" is speculative. There is no evidence of metallic mould-boards coming from China to Europe in time to be used as models by European makers of ploughs. (Chinese mould-boards, incidentally, were made of an alloy, cast iron, rather than of plain iron.) In Europe, wooden mould-boards were simply covered by more and more iron sheets to protect against wear. In some regions, wooden mould-boards were made with a curve from late medieval times.

Finally, wooden mould-boards had their own advantages. In the Gâtinais, north of Orléans, for example, arable soils are quite clayey and stick to iron mouldboards, whereas wooden mould-boards get soaked on their surface, forming a lubricating film of water that prevents the earth from sticking to it. Hence wooden mould-boards were used in this area even when ploughs were made completely of iron, up until the era of the tractor.

François Sigaut

Centre d'Histoire des Techniques, Conservatoire National des Arts et Métiers, 5 rue du Vertbois, 75003 Paris, France

\section{so animals could pull their weight, and more}

Sir - Vaclav Smil's Millennium Essay "Horse power" presents a good overview of the important role of draught horses in agricultural production in North America during the last century ${ }^{1}$. Some points worth adding are that mules were another key source of draught power on many farms ${ }^{2}$, and that the larger draught-horse breeds are, during brief exertions, capable of developing even more than the three horsepower Smil mentions.

Records of draught-horse championship pulling trials in the United States show that a team of two animals could develop 30 horsepower when pulling loads over a set distance ${ }^{3}$. Similar performances have been recorded for teams in Europe and elsewhere. Average working performance for one horse is 0.75 to 1.0 horsepower ${ }^{4}$.

\section{Michael R. Goe}

Department of Animal Sciences, Swiss Federal Institute of Technology, Tannesstrasse 1, ETH-Zentrum, 8092 Zurich, Switzerland

\section{Smil, V. Nature 405, 125 (2000). \\ 2. Leaflet 225 "Quick Reference Map of Horses and Mules by States" (Horse and Mule Association of America, Chicago, 1936). \\ 3. Collins, E. V. \& Caine, A. B. Testing Draft Horses (Iowa Experiment Station Bulletin 240, Ames, 1926). \\ 4. Goe, M. R. \& McDowell, R. E. Animal Traction: Guidelines for Utilization (Cornell International Agriculture Mimeograph 81, Ithaca, NY, 1980). \\ Fraud: retracted articles are still being cited}

Sir-Much heat continues to be generated by the topic of scientific fraud. In the United States, the Office for Research Integrity identifies papers in the biomedical sciences declared to be fraudulent after an official inquiry (http://ori.dhhs.gov) and publishes their bibliographic data.

In addition, papers are often retracted from journals after publication for other reasons. But are these data being generally disseminated?

There are some grounds for pessimism. Kochan and Budd ${ }^{1}$, for example, showed that retracted papers by John Darsee continued to be positively cited even though a considerable amount of time had passed since retraction, and even though the case generated much publicity. Pfeifer and Snodgrass ${ }^{2}$ recorded citations to 82 completely retracted articles and found that, although retraction reduces subsequent citation compared with a control group, retracted papers were often cited to support claims. Finally, Budd et $a l^{3}{ }^{3}$, using Medline to identify articles retracted between 1966 and 1997, found that many retracted articles were still being cited as valid.

It seems, therefore, that in at least some cases, authors are not aware of retractions.

A systematic screening method is required to prevent the citation of fraudulent or retracted papers. This could be done for some disciplines via databases such as Medline (which can be searched for retracted publications), but would not cover all fields of research.

Another approach would be for an organization, for example a scientific publishers' group, to run a web-based database of retracted and/or fraudulent papers covering all fields of research. Authors could then search this database before submitting their papers for publication. This search could be a requirement for submission of the paper to a journal.

Such a database could also help people to avoid doing new research based on useless claims in the literature.

How such a venture would be funded, and how it would work in practice, are the next questions to address.

\section{Juan Miguel Campanario}

Departamento de Fisica, Universidad de Alcala, 28871 Alcala de Henares, Madrid, Spain

$$
\begin{aligned}
& \text { 1. Kochan, C. A. \& Budd, J. M. J. Am. Soc. Inform. Sci. 43, 488-493 } \\
& \text { (1992). } \\
& \text { 2. Pfeifer, M. P. \& Snodgrass, G. L. J. Am. Med. Assoc. 263, } \\
& \text { 1420-1423 (1990). } \\
& \text { 3. Budd, J. M., Sievert, M. E. \& Schultz, T. R. J. Am. Med. Assoc. } \\
& \text { 280, 296-297 (1998). }
\end{aligned}
$$

The Editor replies - Nature requires authors to have performed appropriate checks before submission to ensure the validity of references cited as far as is possible. Nature also has a policy of publishing retractions and corrections. These are linked to and from the relevant paper on the Nature website.

\section{Award organizers should have noted the paper}

Sir - In the News story "Ig Nobel glory for levitating frogs and collapsing toilets" (Nature 407, 665; 2000), my name, listed as one of the co-winners of the Ig Nobel psychology prize for the paper "Unskilled and unaware of it: How difficulties in recognizing one's own incompetence leads to inflated self-assessments", was misspelt - as it is on the Ig Nobel website. It is Kruger, not Kreuger.

This accident is hardly surprising, however, in light of our topic. It can be very difficult to spot one's own mistakes. Justin Kruger

Department of Psychology, University of Illinois in Urbana-Champaign, 603 East Daniel Street,

Champaign, Illinois 61820, USA 